\title{
Now Disease Reports \\ First report of binucleate Rhizoctonia AG U causing black scurf on potato tubers in Japan
}

\author{
T. Misawa ${ }^{1 *}$ and D. Kurose ${ }^{2}$ \\ ${ }^{1}$ Donan Agricultural Experiment Station, Hokkaido Research Organization, Honcho, Hokuto, Hokkaido 041-1201, Japan; ${ }^{2}$ \\ CABI Europe-UK, Bakeham Lane, Egham, Surrey TW20 9TY, UK
}

*E-mail: misawa-tomoo@hro.or.jp

Received: 27 Sep 2018. Published: 01 Dec 2018. Keywords: anastomosis group, fungal plant disease, host range, Solanum tuberosum

Black scurf is caused by the development of sclerotia of the fungus
Rhizoctonia on tubers of potato (Solanum tuberosum). In August 2016,
potato plants (cv. Inca-no-Mezame) with black scurf on their progeny
tubers were observed in Hokkaido, Japan. Diseased tubers had dark brown
to black sclerotia that were irregularly shaped and $1-3 \mathrm{~mm}$ in diameter (Fig.
1). In the 0.2 ha field that was affected, approximately $1 \%$ of the plants had
symptoms.

Surface-sterilised tuber segments that included sclerotia were placed on potato dextrose agar (PDA) containing streptomycin sulphate $(20 \mathrm{mg} / \mathrm{l})$, followed by incubation at $25^{\circ} \mathrm{C}$ for three days. Rhizoctonia-like fungi were frequently recovered. A pure culture, designated as isolate PRT1, was obtained. Hyphae of the isolate were 4.6 to $7.6 \mu \mathrm{m}$ wide (mean $5.9 \mu \mathrm{m}$ ) with two nuclei per cell. A 21-day old PDA culture of the isolate was pale brown in colour with abundant aerial mycelia and dark brown sclerotia, c. 1 $\mathrm{mm}$ in diameter (Fig. 2). To determine the anastomosis group (AG), the rDNA ITS region was sequenced using previously described methods (Misawa et al., 2018). The resulting sequence for PRT1 (GenBank Accession No. LC416305) was $100 \%$ identical to another binucleate Rhizoctonia (BNR) AG U sequence (HQ269825). The isolate was deposited as MAFF 246778 in the NARO Genebank, Japan.

BNR AG U isolates are known to be pathogens of rose (Hyakumachi et al., 2005), carrot (Misawa \& Toda, 2013) and Welsh onion (Misawa et al., 2017). Little is known about the host range of individual AG U isolates so three AG U reference isolates from carrot (isolate NRRS1), Welsh onion (WLS21) and rose (MWR-24) were included in the potato pathogenicity test with isolate PRT1. Potato seed tubers (cv. May Queen) were planted in 13.5 litre pots filled with approximately 6 litres of potting soil (Pottace, Katakura Chikkarin Co., Tokyo, Japan), which had been autoclaved at $121^{\circ} \mathrm{C}$ for 60 minutes. Plants were then grown for one month prior to inoculation with $50 \mathrm{~g}$ of wheat bran inoculum. Sterile wheat bran was used to inoculate control plants. Inoculated plants were grown outside in field conditions (average temperature $17.6^{\circ} \mathrm{C}$ ). Twelve days after inoculation (dai), additional soil was added to completely fill the pots to simulate ridging. Each inoculation test consisted of two pots each containing one plant per isolate. Plants were harvested 76 dai and at least $20 \mathrm{~g}$ of progeny tubers were present in each pot (13-19 tubers). Inoculation with any of the AG U isolates resulted in black scurf on the progeny tubers (Fig. 3). Disease incidence on the tubers inoculated with isolates PRT1, NRRS1, WLS21 and MWR-24 was 57.9\%, 40.6\%, 18.9\% and 92.3\%, respectively. Black scurf was not observed on tubers from the control plants. For each isolate, BNR AG U was re-isolated from the affected tubers therefore fulfilling Koch's postulates. Carrot and Welsh onion plants were also inoculated with isolate PRT1 and the three reference isolates using methodology described previously (Misawa \& Toda, 2013: Misawa et al., 2017). All four AG U isolates caused black scurf on carrot roots at 31 dai (Fig. 4) and leaf sheath rot on Welsh onion at 7 dai (Fig. 5).

This is the first report of BNR AG U causing black scurf in potato crops in Japan. The presence of this tuber blemish pathogen could reduce marketable yields through quality losses. Vegetable growers in Japan may need to consider its presence when growing potato, Welsh onion and carrot crops.

\section{References}

Hyakumachi M, Priyatmojo A, Kubota M, Fukui H, 2005. New anastomosis groups, AG-T and AG-U, of binucleate Rhizoctonia spp. causing root and stem rot of cut-flower and miniature roses. Phytopathology 95, 784-792. http://dx.doi.org/10.1094/PHYTO-95-0784

Misawa T, Toda T, 2013. First report of black scurf on carrot caused by binucleate Rhizoctonia AG-U. Journal of General Plant Pathology 79, 86-88. http://dx.doi.org/10.1007/s10327-012-0422-6

Misawa T, Kurose D, Kuninaga S, 2017. First report of leaf sheath rot of Welsh onion caused by nine taxa of Rhizoctonia spp. and characteristics of the pathogens. Journal of General Plant Pathology 83, 121-130. http://dx.doi.org/10.1007/s10327-017-0706-y

Misawa T, Kurose D, Mori M, Toda T, 2018. Characterization of Japanese Rhizoctonia solani AG-2-1 isolates using rDNA-ITS sequences, culture morphology, and growth temperature. Journal of General Plant Pathology 84, 387-394. http://dx.doi.org/10.1007/s10327-018-0808-1

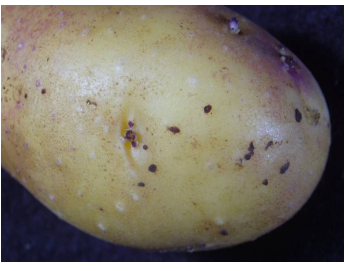

Figure 1

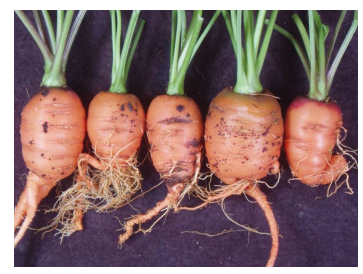

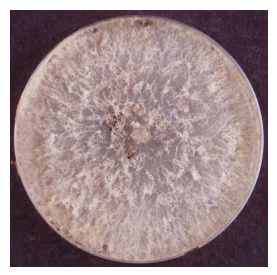

Figure 2

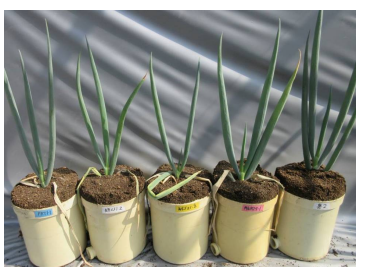

Figure 3

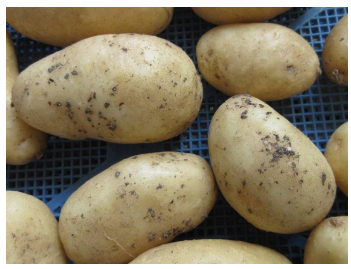

Figure 4

Figure 5

To cite this report: Misawa T, Kurose D, 2018. First report of binucleate Rhizoctonia AG U causing black scurf on potato tubers in Japan New Disease Reports 38, 24. http://dx.doi.org/10.5197/j.2044-0588.2018.038.024

(C) 2018 The Authors

This report was published on-line at www.ndrs.org.uk where high quality versions of the figures can be found. 